\title{
DOSAGEM DE ATIVIDADE ENZIMÁTICA DE FUNGOS FILAMENTOSOS PRODUTORES DE ENZIMAS PECTINOLÍTICAS
}

\author{
O. DOMINGUES ${ }^{1}$, B. F. IZIDORO ${ }^{1}$, F. P. PICHELI ${ }^{1}$, A. V. DE PAULA ${ }^{1}$ e E. A. L. \\ GATTÁS ${ }^{2}$ \\ ${ }^{1}$ Universidade Estadual Paulista, Departamento de Bioprocessos e Biotecnologia \\ ${ }^{2}$ Universidade Estadual Paulista, Departamento de Alimentos e Nutrição \\ E-mail para contato: otavio_domingues2013@hotmail.com
}

\begin{abstract}
RESUMO - O presente trabalho teve como objetivo a análise e caracterização de fungos coletados no Campus Universitário da UNESP de Araraquara através do cultivo em meio sólido e líquido, quanto a produção de enzimas pectinolíticas. Primeiramente, os fungos foram inoculados em meio sólido, contendo pectina cítrica, para o desenvolvimento e posterior análise do halo de crescimento e degradação da pectina do meio. Posteriormente, os fungos foram inoculados em meio líquido, avaliando-se três diferentes fontes de nitrogênio: extrato de levedura, peptona e triptona. Após o período de 7 dias de crescimento em estufa bacteriológica os meios foram filtrados à vácuo e realizada a dosagem da atividade enzimática, pelo método do ácido 3,5-dinitrosalicílico (DNS) para determinação de açúcares redutores. Os melhores resultados foram obtidos com o uso da triptona como fonte de nitrogênio. Foram quantificados os valores de atividade pectinolítica e os fungos foram classificados quanto à produção da enzima desejada. Após os resultados obtidos, conclui-se que não há obrigatoriedade de semelhança entre o melhor fungo em crescimento e o produtor da enzima desejada, sendo destaque o fungo CFCF.
\end{abstract}

\section{INTRODUÇÃO}

Enzimas pectinolíticas, ou pectinases, são um grupo diversificado de enzimas presentes em fungos filamentosos, leveduras e bactérias que possuem a capacidade de degradação de substâncias pécticas comuns a biomassa vegetal (Uenojo, Pastore, 2007). Possuem a capacidade de hidrolisar pectina, um polissacarídeo presente na parede celular e na lamela média das plantas (Alkorta et al., 1998) e que pode ser utilizado como agente emulsionante, gelificante, e como estabilizador na indústria alimentar (Rao, Silva, 2006).

A atuação dessas enzimas na indústria de alimentos é de extrema importância na produção de bebidas por reduzir o amargor característico de citrus, diminuir viscosidade e a turbidez de sucos concentrados, na transformação de frutas e legumes, na produção de vinho, na extração de azeite e em inúmeros outros processos (Dalbøge, 1997). Esta demanda funcional em nível industrial torna crescente a busca por métodos viáveis e eficazes para obtenção destas e seus produtores. As pectinases microbianas constituem cerca de $25 \%$ do comércio de enzimas alimentares no mundo (Sing et al., 1999), destacando-se como principal 
fonte os fungos filamentosos, que foram utilizados por mais de 50 anos nas indústrias de alimentos (Dalbøge, 1997). A capacidade de produção destas enzimas microbianas está ligada à disponibilidade de fontes de nitrogênio e carbono além das condições de cultivo dos mesmos (Uenojo, Pastore, 2007).

No presente trabalho, 4 fungos (KW4, CFCF, HC1, L1) foram analisados, identificados e testados a fim de estipular o melhor produtor da enzima e o meio ideal para seu desenvolvimento.

\section{METODOLOGIA}

\subsection{Caracterização e registro fotográfico}

Os fungos foram repicados em placas de Petri, $90 \mathrm{~mm}$ x $15 \mathrm{~mm}$, contendo meio de pectina cítrica $1 \%(\mathrm{~m} / \mathrm{v})$, peptona $0,5 \%(\mathrm{~m} / \mathrm{v})$, fosfato diácido de potássio $0,1 \%(\mathrm{~m} / \mathrm{v})$, sulfato de magnésio $0,05 \%(\mathrm{~m} / \mathrm{v})$ e ágar $1,8 \%(\mathrm{~m} / \mathrm{v})$, previamente esterilizados em autoclave (15 minutos, $121^{\circ} \mathrm{C}, 1 \mathrm{~atm}$.). Para inoculação foi utilizado uma agulha bacteriológica, na qual apenas uma quantidade mínima de esporos dos fungos deve ser passada para o centro da placa. Após o período de incubação por $24 \mathrm{~h}$ e $48 \mathrm{~h}$ em estufa bacteriológica a $30{ }^{\circ} \mathrm{C}$, foram feitas medidas utilizando régua milimetrada dos halos de crescimento dos fungos e de consumo de pectina nas placas. Posteriormente as placas foram fotografadas. $\mathrm{O}$ halo foi revelado com o corante vermelho de rutênio $0,5 \%(\mathrm{~m} / \mathrm{v})$.

\subsection{Repique e crescimento do fungo em meio de cultivo líquido e filtração}

Inicialmente cada um dos 4 fungos foram repicados em placas de Petri, $90 \mathrm{~mm}$ x 15 mm, contendo meio batata - destrose - ágar (BDA) (39 g/L). Após 7 dias em estufa bacteriológica os fungos crescidos nas placas foram inoculados em meio BDA líquido. Utilizando tubos de ensaio ( $8 \mathrm{~mm}$ de diâmetro), 8 discos de micélio foram retirados de cada placa e inoculados em frascos Erlenmeyers de $250 \mathrm{~mL}$ contendo $50 \mathrm{~mL}$ de meio de cultivo líquido com a seguinte composição: $10 \mathrm{~g} / \mathrm{L}$ de sulfato de magnésio, $10 \mathrm{~g} / \mathrm{L}$ fosfato diácido de potássio, $10 \mathrm{~g} / \mathrm{L}$ de cloreto de cálcio, $10 \mathrm{~g} / \mathrm{L}$ de triptona e $50 \mathrm{~g} / \mathrm{L}$ de pectina cítrica. $\mathrm{O}$ cultivo foi mantido em estufa bacteriológica por 7 dias a $30{ }^{\circ} \mathrm{C}$. Após o crescimento, os meios fermentados foram filtrados à vácuo para recuperação da biomassa e do caldo contendo enzimas. A fase líquida obtida de cada filtração foi utilizada para a dosagem da atividade enzimática.

\subsection{Curva de calibração - açúcares redutores}

Para quantificação dos açúcares formados durante a ação das enzimas contidas nos caldos fermentados sobre substrato de pectina, foi feito uma curva de calibração com o padrão de ácido galacturônico $(5 \mathrm{mg} / \mathrm{mL})$ submetido a reação de determinação de açúcares redutores pelo método do ácido 3,5-dinitrosalicílico (DNS) (Miller, 1959). A solução padrão estoque foi diluída conforme demanda e a reação se deu adicionando $0,5 \mathrm{~mL}$ do padrão diluído a $0,5 \mathrm{~mL}$ do reativo contendo DNS em tubo de ensaio submetido a fervura por 5 minutos. Em seguida resfriado e acrescido de $5 \mathrm{~mL}$ de água destilada para posterior leitura em $540 \mathrm{~nm}$ em espectrofotômetro UV-Visível. Medidas foram realizadas em triplicata. 


\subsection{Dosagem da atividade enzimática}

Para a dosagem de atividade enzimática, o método a ser utilizado foi o de Miller (1959). Preparou-se uma solução de pectina cítrica $1 \%(\mathrm{~m} / \mathrm{v})$ em tampão de acetato de sódio $(50 \mathrm{mM}$, pH 5,5). Em tubos de ensaio, foram adicionados $2 \mathrm{~mL}$ da solução de pectina e $0,5 \mathrm{~mL}$ do filtrado diluído, proporção: 1:10. Os tubos foram deixados em banho-maria $\left(37^{\circ} \mathrm{C}\right)$ por 30 minutos. Em seguida, realizou-se a reação com o reativo de DNS conforme descrito para a curva de calibração. O branco analítico se deu pela substituição de caldo fermentado filtrado por solução tampão acetato de sódio.

\section{RESULTADOS E DISCUSSÕES}

\subsection{Caracterização e registro fotográfico}

Após a incubação das placas inoculadas de esporos, foi realizada a medição das colônias e dos halos de degradação da pectina e o registro fotográfico dos mesmos. Dados contidos nas Tabelas 1 e 2, respectivamente.

Tabela 1 - Colônia e halo de degradação

\begin{tabular}{|c|c|c|c|c|}
\hline Fungo & Colônia 24h $(\mathrm{cm})^{*}$ & Colônia 48h $(\mathrm{cm})^{*}$ & Halo 24h $(\mathrm{cm})^{*}$ & Halo 48h $(\mathrm{cm})^{*}$ \\
\hline \hline L1 & $0,8 \pm 0,05$ & $2 \pm 0,05$ & $1 \pm 0,05$ & $2,4 \pm 0,05$ \\
\hline KW4 & $0,6 \pm 0,05$ & $1,8 \pm 0,05$ & $1 \pm 0,05$ & $2,5 \pm 0,05$ \\
\hline CFCF & $1 \pm 0,05$ & $2 \pm 0,05$ & $1,4 \pm 0,05$ & $2,5 \pm 0,05$ \\
\hline HC1 & $0,8 \pm 0,05$ & $2 \pm 0,05$ & $1 \pm 0,05$ & $2,5 \pm 0,05$ \\
\hline KW9 & $0,5 \pm 0,05$ & $1,8 \pm 0,05$ & $0,8 \pm 0,05$ & $2,3 \pm 0,05$ \\
\hline
\end{tabular}

*medida \pm desvio padrão

De acordo com a Tabela 1, foi possível concluir que o fungo KW4 mostra-se com melhor crescimento tanto de colônia $(1,2 \mathrm{~cm})$ quanto do halo de degradação $(1,5 \mathrm{~cm})$, obtendo uma maior diferença entre os tamanhos da colônia e dos halos nos períodos de $24 \mathrm{~h}$ e $48 \mathrm{~h}$, se comparado aos demais fungos.

Tabela 2 - Colônia e halo de degradação (Fotos)

\begin{tabular}{|c|c|c|c|}
\hline KW4 & CFCF & HC1 & L1 \\
\hline \hline $24 h$ & $24 h$ & $24 h$ & $24 h$ \\
\hline & & & \\
\hline $48 h$ & & & \\
\hline & $48 h$ & $48 h$ & $48 h$ \\
\hline & & & \\
\hline & & & \\
\hline
\end{tabular}




\subsection{Curva de calibração}

Inicialmente, construiu-se uma curva de calibração do ácido galacturônico, apresentada na Figura 1.

Figura 1 - Curva de calibração do acido galacturônico

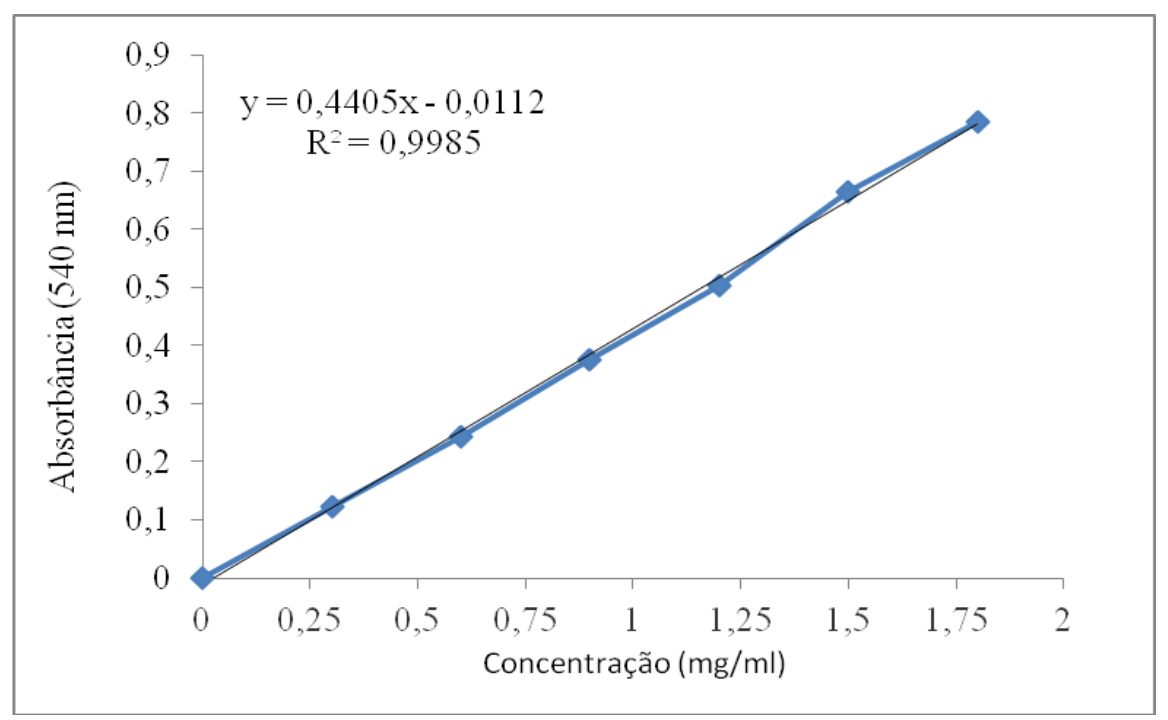

Observa-se uma boa relação entre a concentração de ácido galacturônico e absorbância, sendo possível a partir dos dados obtidos calcular a atividade enzimática de cada filtrado.

\subsection{Dosagem de atividade}

Após o cultivo em meio sólido, os fungos foram inoculados em meio líquido para a dosagem da atividade enzimática. Os dados da atividade dos 4 fungos estão na Tabela 4.

Tabela 4 - Atividade enzimática dos diferentes fungos

\begin{tabular}{|c|c|}
\hline Fungo & Atividade (mmol/mLmin) \\
\hline \hline KW4 & $73,245 \pm 0,258$ \\
\hline CFCF & $339,376 \pm 81,111$ \\
\hline HC1 & $217,361 \pm 19,632$ \\
\hline L1 & $110,872 \pm 83,436$ \\
\hline \multicolumn{2}{|c|}{ *medida \pm desvio padrão }
\end{tabular}

A fim de facilitar a comparação dos resultados obtidos, a partir dos dados da tabela 4, construiu-se a Figura 2, que relaciona a atividade enzimática e o fungo avaliado. 
Figura 2 - Quantificação da atividade enzimática

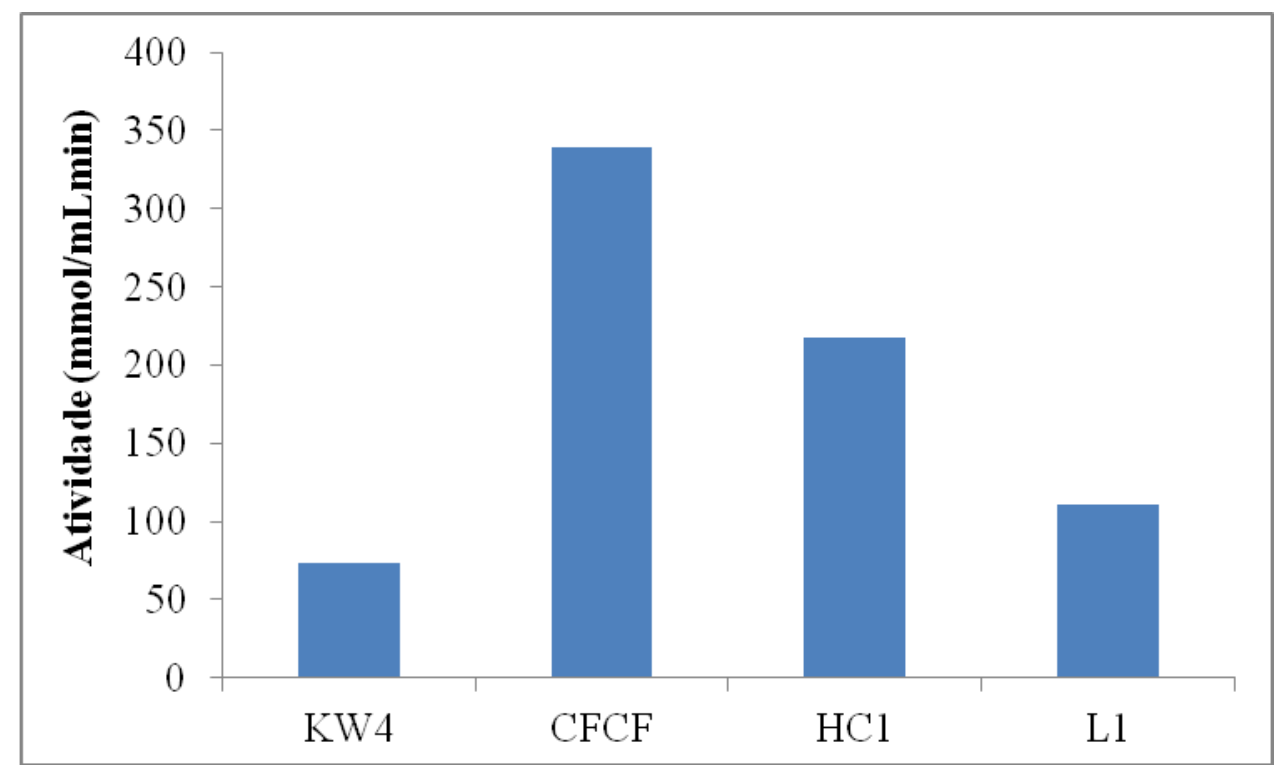

De acordo com os resultados obtidos, o fungo que forneceu enzima com maior atividade foi o CFCF, seguido dos fungos $\mathrm{HC1}$, L1 e KW4. Dentre os fungos capazes de produzir enzimas pectinolíticas no meio de cultivo, o fungo Aspergillus $s p$. CFCF-0492 apresentou a maior atividade enzimática $(15,0 \mathrm{mmol} / \mathrm{mLmin})$ quanto aos demais fungos em crescimento isolado (Gattás et al., 2003). Entretanto, a atividade enzimática do CFCF mostrou-se superior à obtida na utilização de Aspergillus niger na fermentação submersa em meio Czapeck enriquecido com uso de casca de laranja como fonte de carbono, apresentando uma atividade de $117.1 \pm 3,4 \mathrm{mmol} / \mathrm{mLmin}$ (Ahmed et al, 2016.). Dessa forma, os resultados obtidos nas dosagens das atividades são positivos quando comparados com as atividades apresentadas pelos trabalhos utilizados como base para o projeto.

\section{CONCLUSÃO}

Com base nas análises do registro fotográfico destaca-se o fungo KW4 com o maior crescimento mensurado. O CFCF mostra-se como o segundo melhor no crescimento da colônia e dos halos, sendo o que forneceu maior atividade enzimática. Não houve relação direta entre o melhor fungo em termos de crescimento e aquele que fornece maior atividade enzimática. Portanto, dentre os fungos avaliados no presente estudo, o CFCF foi o melhor fungo, devendo ser explorado em estudos futuros.

\section{REFERÊNCIAS}

AHMED, I.; ZIA, M. A.; HUSSAIN, M. A.; AKRAM, Z.; NAVEED, M. T.; NOWROUZI, A. Bioprocessing of citrus waste peel for induced pectinase production by Aspergillus niger; its purification and characterization. Journal of Radiation Research and Applied Sciences, v 9, p. $148-154,2016$.

ALKORTA, I.; GARBISU, C.; LLAMA, M. J.; SERRA, J. L. Industrial applications of pectic enzymes: a review. Process Biochemistry, v. 33, n. 1, p. $21-28,1998$. 
DALBØGE, H. Expression cloning of fungal enzyme genes: a novel approach for efficient isolation of enzyme genes of industrial relevance. FEMS Microbiology, n. 12, p. $29-42,1997$.

GATTÁS, E. A. L.; CANGUÇU, U. M.; RAMOS, W. S.. Isolamento de fungos produtores de enzimas pectinolíticas. Revista de Ciências Farmacêuticas, v. 24, n. 1, p. 33 - 37, 2003.

MOHNE, D. Pectin structure and biosynthesis. Current Opinion in Plant Biology, v. 11, p. $266-277,2008$.

RAO, M., SILVA, J. L. Pectins: Structure, functionality, and uses. In: Food Polysaccharides and Their Applications. Eds. STEPHEN, A. M., PHILLIPS, G. O., WILLIANS, P. A. Ed. Boca Raton. CRC Press. Florida, p. 353 - 411, 2006.

SINGH, S. A.; RAMAKRISHNA, M.; RAO, A. G. A. Optimization of downstream processing parameters for the recovery of pectinase from the fermented broth of Aspergillus carbonarious. Process Biochem 1999; 35:411-7.

UENOJO, M.; PASTORE, G. A. Pectinases: aplicações industriais e perspectivas. Química Nova, v. 30, n. 2, p. $388-394,2007$. 